\title{
Hereditary cancer syndromes in Latino populations: genetic characterization and surveillance guidelines
}

\author{
Marcia Cruz-Correa ${ }^{1,2,8^{*}}$, Julyann Pérez-Mayoral ${ }^{1,2}, J_{u l i e ~ D u t i l}{ }^{3}$, Miguel Echenique $^{4}$, Rafael Mosquera ${ }^{5}$, \\ Keila Rivera-Román ${ }^{6}$, Sharee Umpierre ${ }^{1}$, Segundo Rodriguez-Quilichini ${ }^{1}$, Maria Gonzalez-Pons ${ }^{1,2}$, Myrta I. Olivera ${ }^{1,2}$, \\ Sherly Pardo ${ }^{7}$ and on behalf of the Puerto Rico Clinical Cancer Genetics Consortia
}

\begin{abstract}
Hereditary cancer predisposition syndromes comprise approximately $10 \%$ of diagnosed cancers; however, familial forms are believed to account for up to $30 \%$ of some cancers. In Hispanics, the most commonly diagnosed hereditary cancers include colorectal cancer syndromes such as, Lynch Syndrome, Familial Adenomatous Polyposis, and hereditary breast and ovarian cancer syndromes. Although the incidence of hereditary cancers is low, patients diagnosed with hereditary cancer syndromes are at high-risk for developing secondary cancers. Furthermore, the productivity loss that occurs after cancer diagnosis in these high-risk patients has a negative socio-economic impact. This review summarizes the genetic basis, phenotype characteristics, and the National Comprehensive Cancer Network's screening, testing, and surveillance guidelines for the leading hereditary cancer syndromes. The aim of this review is to promote a better understanding of cancer genetics and genetic testing in Hispanic patients.
\end{abstract}

Keywords: Genetic testing, Genetic counseling, Germline mutations, Hereditary cancer, Hispanics

\section{Background}

\section{Hereditary cancer overview}

According to the 2010 census, Hispanics comprise $16.3 \%$ of the population in the United States (US) [1]. By 2050, the Hispanic population is estimated to become $25 \%$ of the US population. Hispanics are a mixed group of individuals from across Latin America and the Caribbean and are defined as individuals that share a culture and language that is linked to the historic migrations that started from Spain that led to the discovery of the Americas. In the year 1492, Christopher Columbus crossed the Atlantic Ocean and reached the Americas. The arrival of Columbus to the Americas led to the start of the "Colonization of Americas", where language, culture and religion was instituted by the Spaniards, but also other European countries such as Portugal.

\footnotetext{
* Correspondence: marcia.cruz1@upr.edu

'Department of Cancer Biology, University of Puerto Rico Comprehensive Cancer Center, San Juan, PR, USA

${ }^{2}$ University of Puerto Rico Medical Sciences Campus, School of Medicine, San Juan, PR, USA

Full list of author information is available at the end of the article
}

Spaniards introduced new diseases to the Americas leading to the death of most of the Indigenous population of the Americas. Due to the high mortality of Indigenous population, Africans (mostly from West Africa) were introduced in the Americas. Through these historic migrations, the Hispanic population was created. These populations had great levels of genetic and cultural admixture from the three major racial ancestral populations: Europeans, Africans, and Indigenous. However, the variability observed in Hispanic admixture, is concordant with the local history of the country of origin [2]. For instance, Hispanics from the Caribbean (including Puerto Ricans) have a higher proportions of West African compared to Hispanics from South America, which have higher European and Amerindian ancestry [2].

Cancer is a major public health problem and the leading cause of death among Hispanics worldwide [3]. Malignancies, such as breast and colorectal cancers, when diagnosed in individuals younger than 50 years, are likely caused by inherited mutations and often are aggressive leading to a worse prognosis [4]. With the availability of efficient screening methods for both breast and 
colorectal cancer, these cancers may be prevented or diagnosed at early, more treatable stages in Hispanics, minimizing the burden of these diseases in this population [5]. By identifying individuals at high-risk and establishing tailored early detection and preventive strategies, the economic productivity loss, morbidity, and mortality may be significantly reduced.

In this article, we provide a summary of the genetic basis for three of the leading cancers in Hispanics (breast, ovarian, and colorectal cancer), which have known hereditary contributions. We will discuss the clinical presentation of these cancers in Hispanics and how it differs from other populations. Furthermore, we will discuss the role of multigene testing in advancing genetic testing services in Latino populations.

\section{Hereditary breast cancer and ovarian cancer (HBOC)}

Breast cancer (BC) represents approximately $29 \%$ of all cancer cases in US Hispanic women [3]. Ovarian cancer $(\mathrm{OC})$ is the $8^{\text {th }}$ cancer with the highest incidence and the $5^{\text {th }}$ leading cause of cancer death among US Hispanic women [3]. Approximately, $5-10 \%$ of all BC are caused by mutations in highly penetrant susceptibility genes [6]. Mutations in the BRCA1 and $B R C A 2$ genes account for approximately $25 \%$ of hereditary $B C$ and $15 \%$ of all OC [7]. Women with mutations in these genes have up to an $87 \%$ lifetime risk of developing $\mathrm{BC}$ by age 70 and up to a $44 \%$ risk of OC $[4,8]$.

\section{Mutation spectrum}

In Hispanics, deleterious BRCA mutations have been found in approximately $25 \%$ of women with $\mathrm{BC}$ [9]. The majority of the studies reporting the prevalence of $B R C A$ mutations in Hispanics have been performed on heterogeneous groups of Hispanic women from different countries, including: Mexico [9-11], Brazil [12-14], Costa Rica [15], Chile [16, 17], Argentina [18], Peru [19], Colombia [20, 21], Venezuela [22], Bahamas [23], Cuba [24], and Puerto Rico [25] (Table 1). Recently, BRCA mutations in Latin American countries was published, which detailed the mutations found and how the prevalence changed from country to country [26]. All of these studies have shown that the $B R C A$ mutation spectrum varies according to the country of origin. For example, women from Argentina, Mexico, and Brazil have a higher prevalence of $B R C A 1$ mutations [13, 18, 27], whereas in women from the Caribbean (Cuba and Puerto Rico), BRCA2 is more frequently mutated [24, $25]$. Studies of women with BC from Spain showed a larger number of rearrangements in both $B R C A$ genes when compared to Hispanic women [28-30]. Additionally, several mutations for both $B R C A$ genes were found in Hispanic subpopulations, especially in Argentina where there is a higher proportion European admixture.
Furthermore, a mutation (BRCA2 c.156_157insAlu) from Portugal was identified in the Northern/Central region and accounted for one-fourth of the $B R C A 1 / 2$ mutations [31]. This same mutation was identified in several families of Brazil [31, 32].

Several populations have shown the presence of founder mutations, which include some Ashkenazi Jew mutations (BRCA1 185delGA; BRCA1 5382insC) observed in Mexico [33], Peru [19], and Brazil [13]. These founder mutations have also been reported in Spain [28-30]. Therefore, these Ashkenazi Jew mutations are thought to come from areas of Spain where Jews communities settled during the early Common Era. The BRCA1 ex9-12 deletion found in Mexican women is also a founder mutation. This mutation has not observed in Spain or South American populations, and was found to pre-date Spanish colonization since it is estimated to have arisen approximately 1,480 years ago $[10,34,35]$ (Table 1). Furthermore, two additional founder mutations of Galician and Spanish origin were found in Spain [28]. Of these, the BRCA1 c.211A > G Galician founder mutation was found in the groups of a US Hispanic and the Argentinian cohort $[11,18]$. Three additional founder mutations: 2 in BRCA1 (BRCA1 c.3331_3334delCAAG and BRCA1 c.5123C>A) and 1 in BRCA2 (BRCA2 c.2806_2809delACAA) where described in Hispanics from Colombia [21]. These Colombian founder mutations were found in individuals that share the same haplotype, and therefore share a common ancestor [21]. The BRCA2 c.3922G > T mutation has only been identified in the Puerto Rican cohort, and in US Hispanic studies that include Puerto Ricans and not in other Latin American countries [26]. In Portugal, the BRCA2 c.156_157insAlu mutation seen in families of Portuguese descent was also identified as a founder mutation that occurred around 558 years ago $[31,32,36]$. Moreover, the BRCA1 c.5266dup mutation was identified as a founder Brazilian mutation of Eastern European origin [37]. The presence of these founder mutations in Latin America is tightly linked to migration patterns that shaped the genetic background of each Hispanic subpopulation up to present-day.

Several studies suggest that the prevalence of $B R C A$ mutations in Hispanic women is higher than the prevalence of $B R C A$ mutations among Ashkenazi Jews and non-Hispanic Whites $[9,11]$. However, these observations are based on the predictability of $B R C A$ genetic risk models that use non-Hispanic White women as reference to determine risk, thus the prevalence of $B R C A$ mutations might differ from what has been reported [9]. Differences observed in the $B R C A$ mutation spectrum of Hispanic populations could be due to variations in the contribution of each ancestral population to the genetic background of the Hispanic subgroups. In addition, 


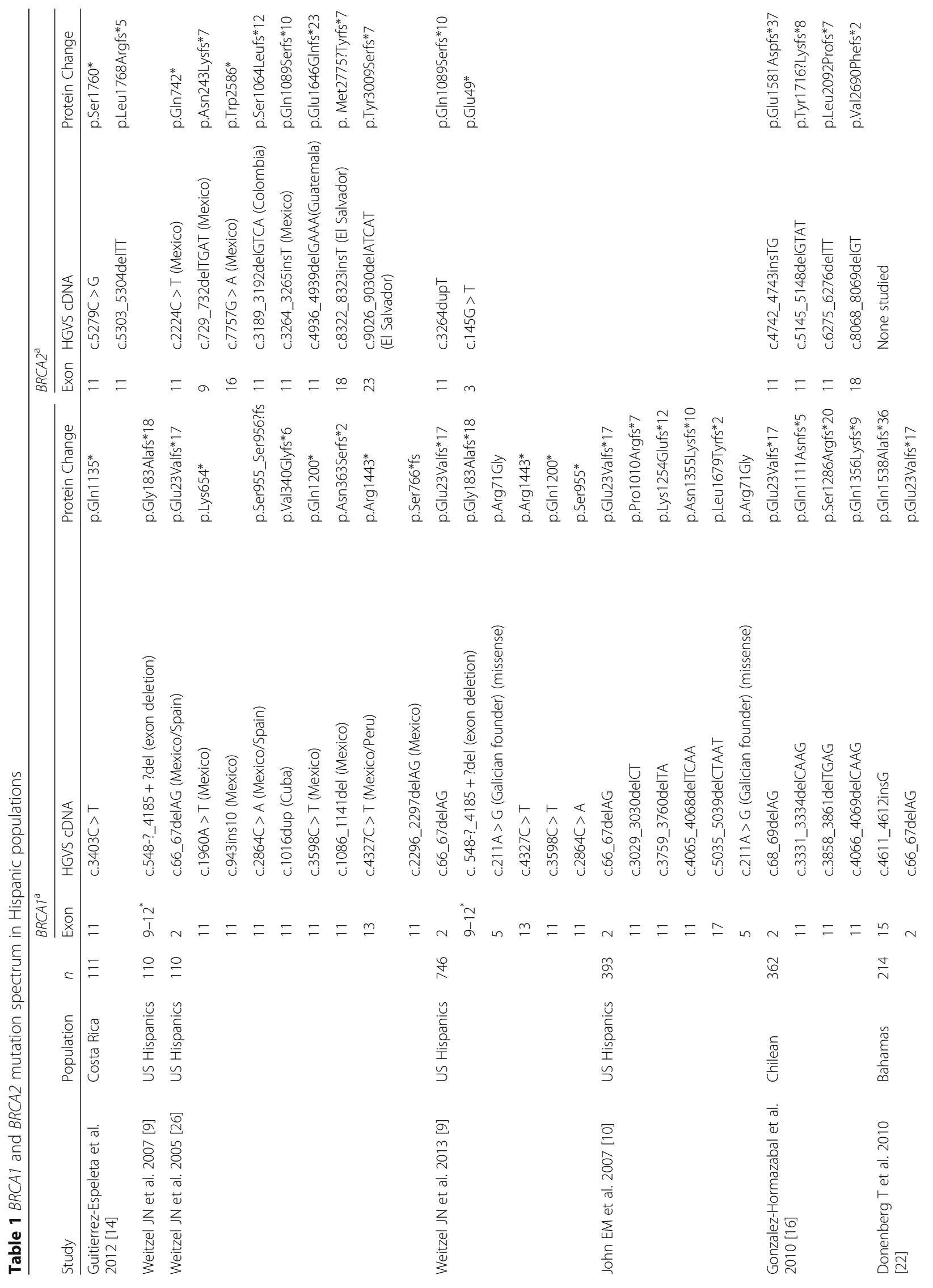




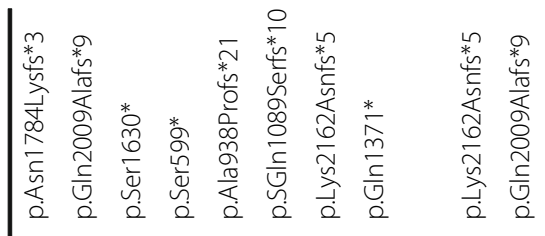

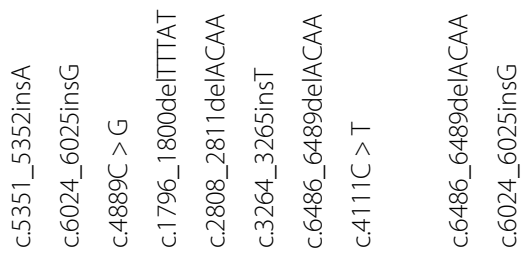

$=\Sigma=E=E=E=$

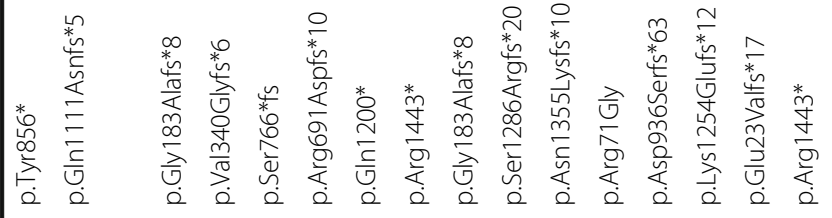

3
$=$
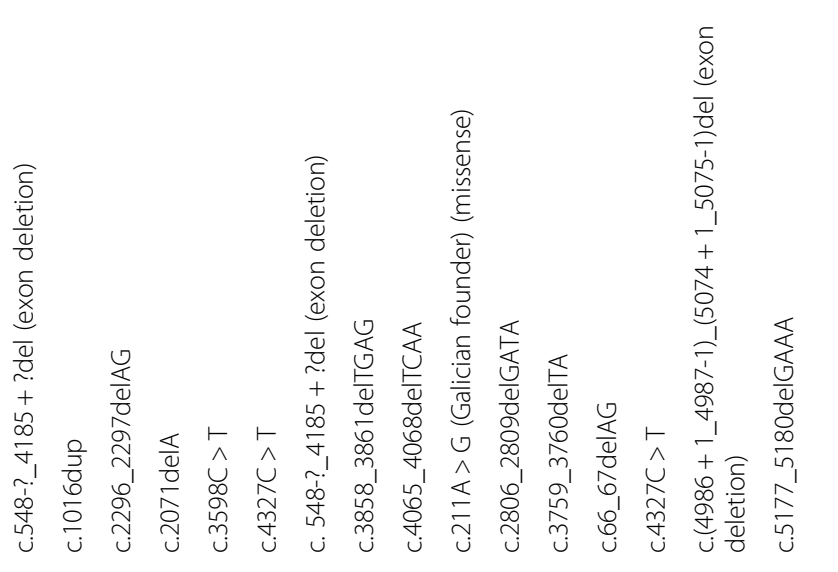

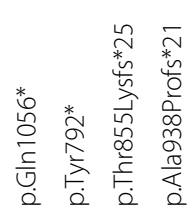
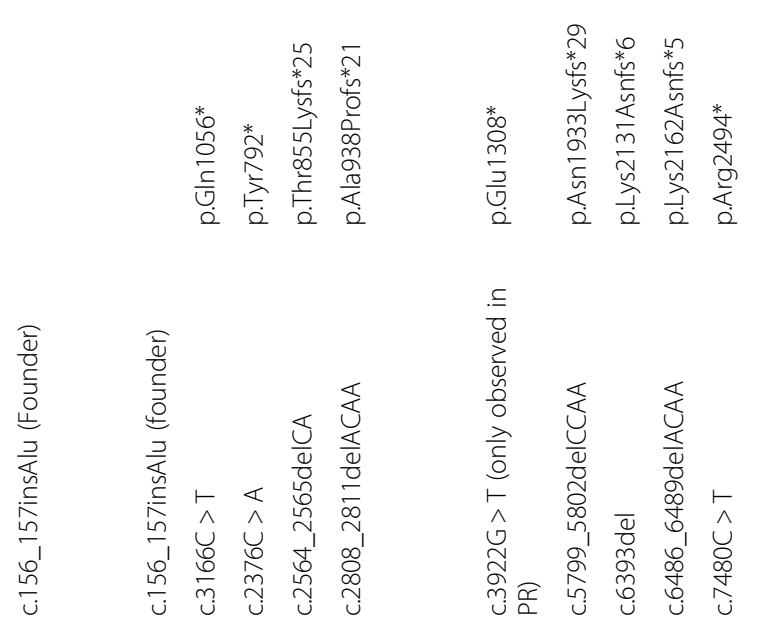

n $==E$

$\stackrel{⿱ ㇒}{\rightleftharpoons} \stackrel{\leftarrow}{=}$

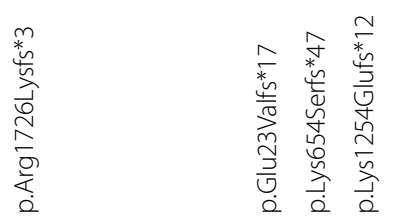

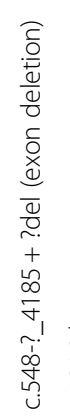

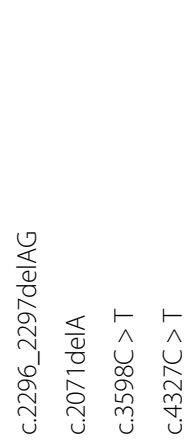

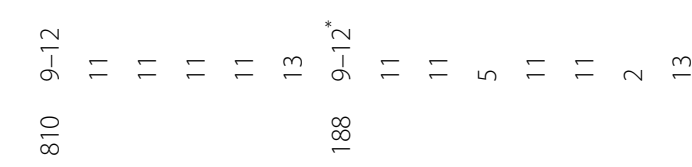

$\underline{n} \underset{c}{\underline{b}}$

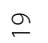

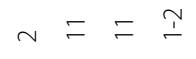

$\equiv \stackrel{\circ}{\infty}$

年 $\quad \stackrel{\circ}{\sim}$ 官

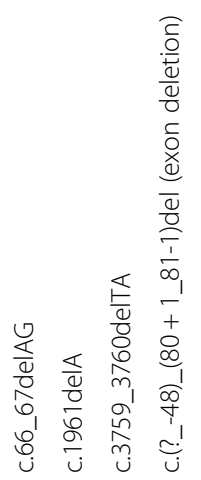

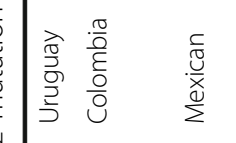

$\stackrel{\stackrel{\mathscr{x}}{\gtrless}}{\sum}$

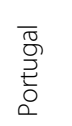

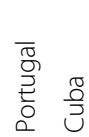

$\stackrel{\sim}{2}$

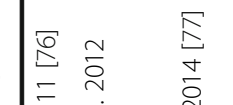

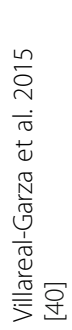

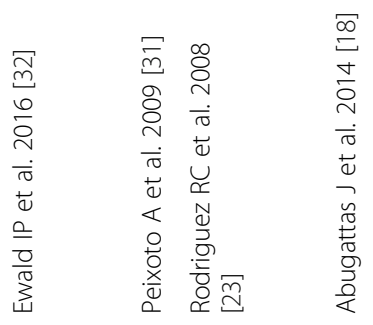

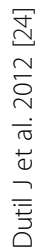



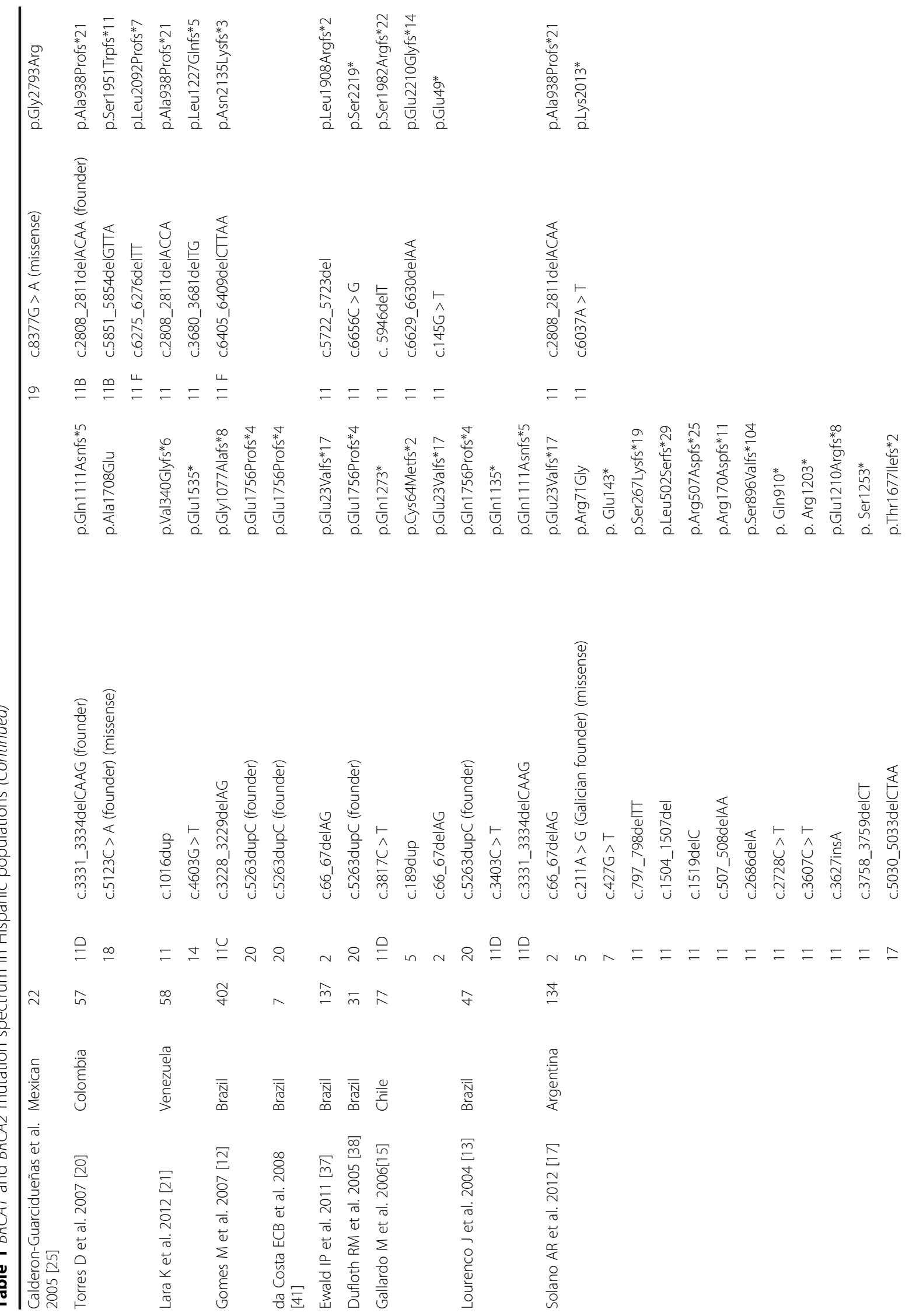

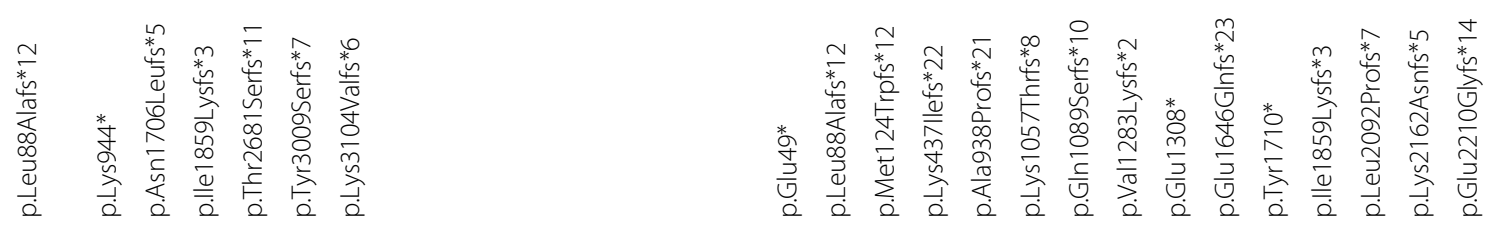

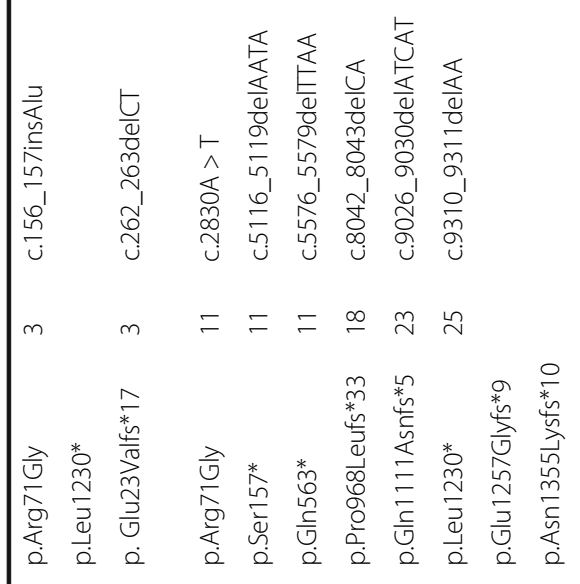

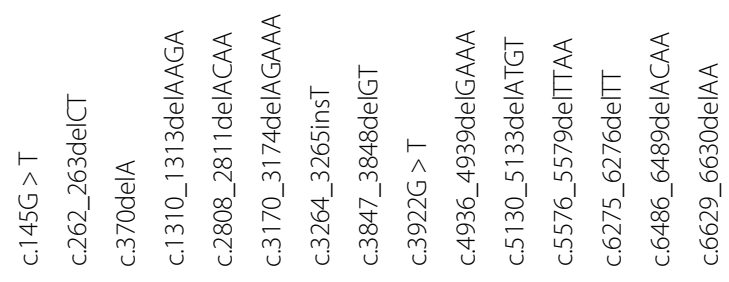

$m n+\circ=E=E=E=E=E$

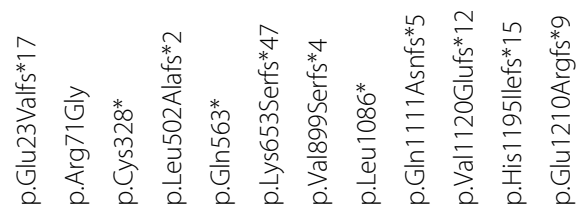

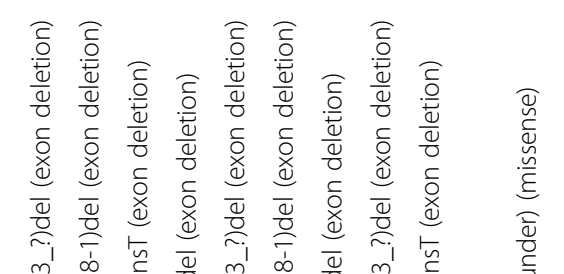

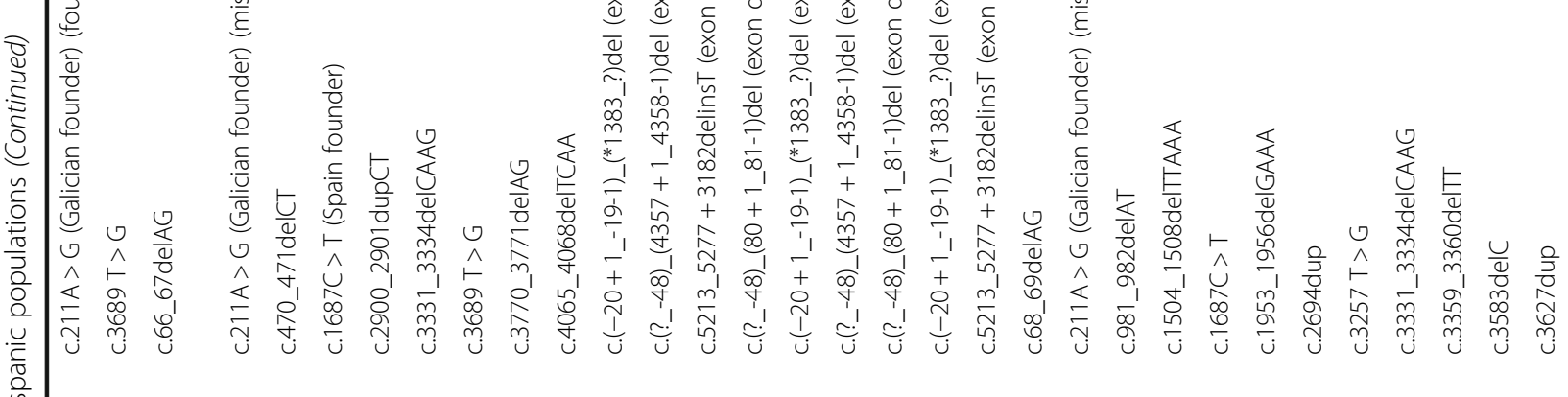

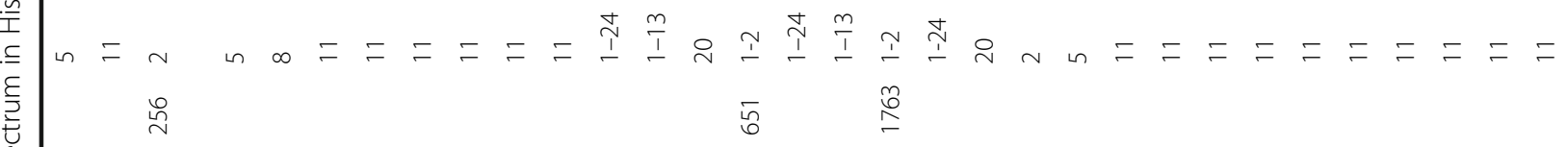

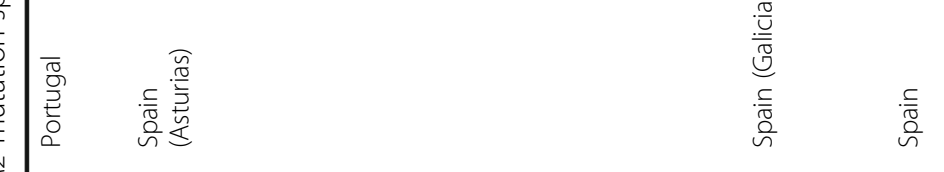


Cruz-Correa et al. Hereditary Cancer in Clinical Practice (2017) 15:3

Page 7 of 15

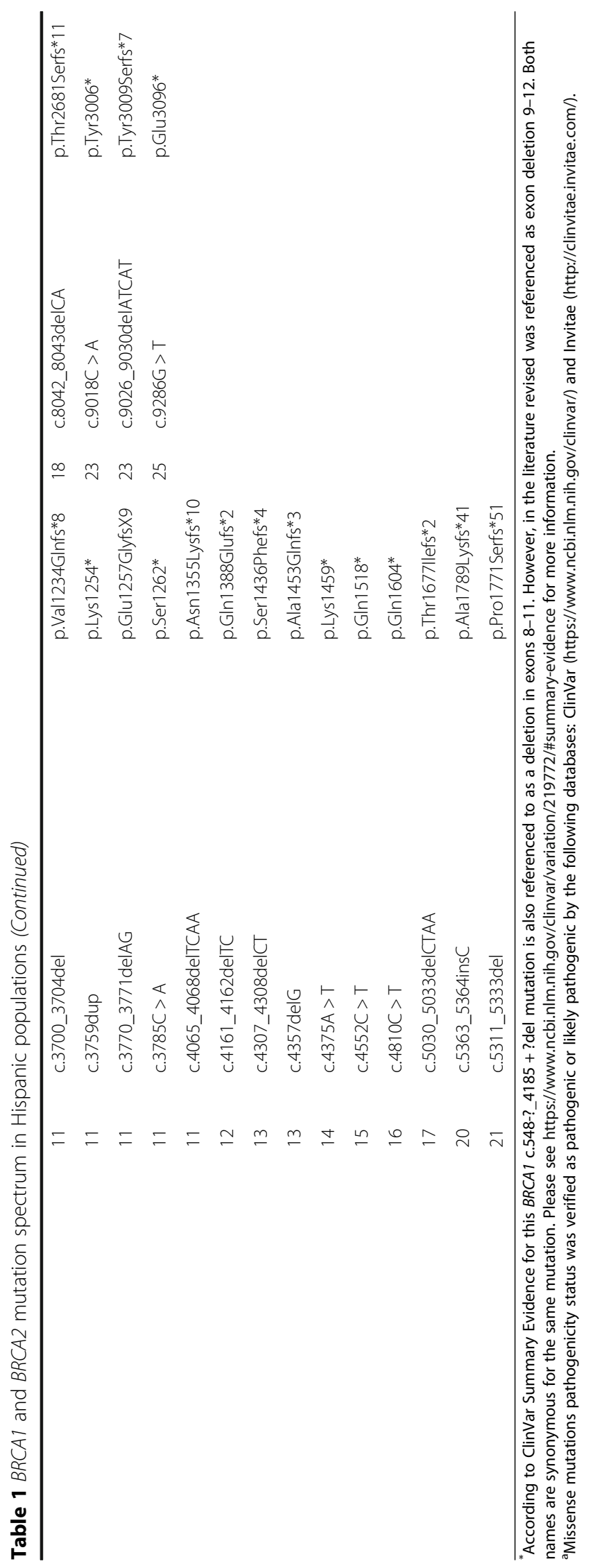


there is very limited information on the mutation spectrum in some countries, such as Costa Rica, Bahama, and Cuba, among others. Therefore, the mutation spectrum of $B R C A$ among Hispanic women is still understudied, which may our knowledge on the true percentage of $\mathrm{BC}$ in Hispanic populations that may be attributable to hereditary changes.

\section{Clinical phenotype}

The clinical presentation of HBOC among Hispanic subpopulations is very similar to non-Hispanic cohorts [12, $17,19,21,25,36-40]$. Most studies reported that the majority of women that met inclusion criteria had $\mathrm{BC}$ diagnosed before age 50 (67.5\%; range: 50.4-81.4\%). Additionally, family history of $\mathrm{BC}$ was found on an average of $16.1 \%$ (range: $5.2-27 \%$ ) of Hispanic women recruited in the studies described in this review. Comparisons of the age at $\mathrm{BC}$ diagnosis among the Hispanic subpopulations described above showed that Caribbean Hispanics (Bahamas, Puerto Rico and Cuba) were diagnosed at later ages (mean: 45.9 years; range: $40-51.8$ years) than their South American (mean: 44 years), Central American (mean: 41.6 years) and US Hispanic (mean: 38.5 years) counterparts $[17,19,21,25,28-30,32,36-41]$.

\section{Clinical guidelines}

The National Comprehensive Cancer Network (NCCN) established guidelines for physicians to evaluate potential candidates for genetic counseling and testing [42]. The evaluation criteria for $\mathrm{HBOC}$ genetic testing include: personal history of $\mathrm{BC}$ before 50 years of age, one or more $1^{\text {st }}$ degree relatives with $\mathrm{BC}$, family history of a BRCA1/2 mutation, and personal history of $\mathrm{OC}$, among others. The information obtained from the genetic tests is used by physicians to guide the patient's medical/surgical management. This management may include chemoprevention therapy, prophylactic surgery (double mastectomy, oophorectomy, and/or hysterectomy), and increased surveillance by mammography and breast MRI. Even though these guidelines have been established, underutilization of these guidelines for Hispanic patients that meet the criteria has been reported [43]. The reason for the low adherence to these guidelines is yet to be addressed, but it is believed that a combination of factors such as, socioeconomic, belief systems, and access to care contribute to this health disparity. Furthermore, the benefits of utilizing these guidelines in other countries, where prevalence of $B R C A$ mutations is high, is still to be determined. For example, the high prevalence of $B R C A$ mutations in the Bahamas supports the implementation of universal testing. However, countries such as Puerto Rico, that have a small number of mutations, could benefit even more from implementing these guidelines. Additionally, it is important to note that these guidelines where developed using studies mainly performed in non-Hispanic White women. Further studies are needed to elucidate whether NCCN guidelines are useful in Hispanic women or if the differences observed in the prevalence of $B R C A$ mutations and clinical presentation, warrants changes to accommodate these differences.

\section{Colorectal cancer syndromes}

Colorectal cancer (CRC) accounts for 11 and $8 \%$ of cancers in US Hispanic males and females, respectively [3]. Hereditary CRC accounts for approximately $5-10 \%$ of all CRC cases. There are two major types of inherited CRC syndromes: 1) Familial Adenomatous Polyposis (FAP) and 2) Lynch Syndrome (LS). In this section, we will discuss the clinical presentation, genetic basis, and guidelines for testing for these two forms of inherited CRC syndromes.

\section{Familial adenomatous polyposis}

FAP is characterized by the presence of hundreds to thousands of adenomatous polyps in the colon and rectum. These polyps appear during adolescence and, if left untreated, can develop into CRC by age 40 . Affected individuals without a colectomy have close to $100 \%$ lifetime risk of developing CRC [44]. By age 20, most patients have at least 1 adenomatous polyp; by age 50, most have developed adenocarcinoma [44]. Thus, the recommended treatment for FAP is prophylactic colectomy in young adulthood [45].

Classic FAP has an incidence ranging from 1 in 8300 people to 1 in 22,000 people, depending on the country of origin [46]. FAP is caused by mutations in the $A P C$ gene [47]. Most cases have a family history of FAP, but close to $25 \%$ of cases are diagnosed as de novo mutations [48]. Identifying the specific $A P C$ mutation in a family can be used for targeted sequencing testing for presymptomatic, at-risk family members.

Mutation spectrum The FAP mutation spectrum has been studied in a limited number of Hispanic countries, including Brazil [49], Argentina [50], Peru [51], Mexico [44], Puerto Rico [52], Portugal, and Spain [53] (Table 2). Most mutations identified in Hispanic patients from both Latin America, Portugal, and Spain have been in exon 15 of the $A P C$ gene (Table 2). This exon comprises more than $75 \%$ of the coding sequence and is the most commonly mutated region of the $A P C$ gene [54].

Clinical phenotype The data available on the clinical manifestation of FAP in Hispanic is limited. Of the studies discussed, only studies from Puerto Rico [52], US Hispanics (from Mexico, Guatemala and Honduras) [51] and Brazil [49] had phenotype information for Hispanic FAP patients. Puerto Rican individuals with FAP had a mean age of diagnosis of 27.6 years (range: 9-71 years), 
Table 2 APC mutation spectrum in Hispanic patients

\begin{tabular}{|c|c|c|c|c|c|}
\hline \multirow[b]{2}{*}{ Study } & \multirow[b]{2}{*}{ Population } & \multirow[b]{2}{*}{$n$} & \multicolumn{3}{|l|}{$A P C^{\mathrm{a}}$} \\
\hline & & & Exons & Mutation & Protein Change \\
\hline \multirow[t]{6}{*}{ Cruz-Correa et al. 2013 [43] } & Puerto Rico & 31 & 15 & c.3183_3187delACAAA & p.Gln1062* \\
\hline & & & 15 & c.4612_4613delGA & p.Glu1538llefs*5 \\
\hline & & & 15 & c.3149delC & p.Ala1050Glufs*6 \\
\hline & & & 15 & c.3927_3931delAAAGA & p.Glu1309Aspfs*4 \\
\hline & & & 14 & c. $1873 C>T$ & p.G $\ln 625^{*}$ \\
\hline & & & 15 & c. $4012 C>T$ & p.Gln1338* \\
\hline \multirow[t]{12}{*}{ Tardin-Torrezan G et al. 2013 [40] } & Brazil & 23 & & del $5 q 21.3-q 22.3$ & \\
\hline & & & 8 & c.856_859dupCATG & p.Glu287Alafs*2 \\
\hline & & & 4 & c.447dupC & p.Lys 150Glnfs*18 \\
\hline & & & 15 & c.4097dupC & p.Gln1367Serfs*8 \\
\hline & & & 8 & C. $904 \mathrm{C}>\mathrm{T}$ & p.Arg302* \\
\hline & & & 15 & $c .4348 C>T$ & p.Arg1450* \\
\hline & & & 15 & c.3880-3881 delCA & p.Gln1294Glyfs*6 \\
\hline & & & 8 & $\mathrm{C} .847 \mathrm{C}>\mathrm{T}$ & p.Arg283* \\
\hline & & & 15 & c. 4099 C > T & p.Gln1367* \\
\hline & & & 15 & c.3050-3053delATGA & p.Asn1017Metfs*4 \\
\hline & & & 15 & c.3927-3931delAAAGA & p.Glu1309Aspfs*4 \\
\hline & & & 15 & c.4393-4394delAG & p.Ser1465Trpfs*3 \\
\hline Zeichner S et al. 2012 [41] & Hispanic & 1 & 15 & c.3927_3931delAAAGA & p.Glu1309Aspfs*4 \\
\hline \multirow[t]{6}{*}{ Ricker C et al. 2010 [42] } & Mexico, Guatemala, Honduras & 9 & 15 & c. $3184 C>T$ & p.Gln1062* \\
\hline & & & 15 & c.3709delCA (MX) & p.Gln1237Glufs*2 \\
\hline & & & & g.89926-?_141606 + ?del (GU) & \\
\hline & & & 15 & c.3927_3931delAAAGA (MX) & p.Glu1309Aspfs*4 \\
\hline & & & 15 & c.3803_3815del1 (HO) & p.Pro1268Glufs*16 \\
\hline & & & 15 & c.3183_3187delACAAA (MX) & p.Gln1062* \\
\hline \multirow[t]{18}{*}{ InSIGHT [53] } & Argentina & & 15 & c.3920 T > A (missense) & p.lle1307Lys \\
\hline & Portugal & & 15 & c.4687dup & p.Leu1563Profs*4 \\
\hline & & & 15 & c.5826_5829delCAGA & p.Asp1942Glufs*27 \\
\hline & Spain & & 5 & c.637C > T & p.Arg213* \\
\hline & & & 6 & c.707delA & p.Gln236Argfs*57 \\
\hline & & & 7 & c.730_731delAG & p.Arg244Valfs*7 \\
\hline & & & 7 & $\mathrm{c} .802 \mathrm{G}>\mathrm{T}$ & p.Glu268* \\
\hline & & & 8 & c.858delT & p.His286Glnfs*7 \\
\hline & & & 8 & C. $904 \mathrm{C}>\mathrm{T}$ & p.Arg302* \\
\hline & & & 11 & c.1412delG & p.Gly471Aspfs*27 \\
\hline & & & 13 & c.1682dupA & p.Thr562Aspfs*19 \\
\hline & & & 13 & c. $1690 C>T$ & p.Arg564* \\
\hline & & & 14 & c. $1787 C>$ G & p.Ser596* \\
\hline & & & 14 & c.1946_1947insG & p.Asn649Lysfs*2 \\
\hline & & & $15 \mathrm{~A}$ & c.1993_1994delTT & p.Leu665llefs*9 \\
\hline & & & 15 & c.2310delA & p.Glu771Lysfs*6 \\
\hline & & & $15 B$ & $c .2413 C>T$ & p.Arg805* \\
\hline & & & $15 C$ & c.2496delC & p.Ser833Alafs*9 \\
\hline
\end{tabular}


Table 2 APC mutation spectrum in Hispanic patients (Continued)

$\begin{array}{lll}\text { 15D } & \text { c.2838_2839delAT } & \text { p.Cys947Phef**15 } \\ \text { 15D } & \text { c.2977A > T } & \text { p.Lys993* } \\ \text { 15D } & \text { c.2980_2990del11 } & \text { p.Phe994Trpfs*10 } \\ 15 E & \text { c.3224dupA } & \text { p.Tyr1075* } \\ \text { 15E } & \text { c.3251_3252dupAT } & \text { p.Lys1085llefs*42 } \\ 15 G & \text { c.3921_3924delAAAA } & \text { p.lle1307Metfs*13 } \\ 15 G & \text { c.3927_3931delAAAGA } & \text { p.Glu1309Aspfs*4 } \\ 15 & \text { c.4260_4261delCA } & \text { p.Ser1421* }\end{array}$

${ }^{a}$ Missense mutations pathogenicity status was verified as pathogenic or likely pathogenic by the following databases: ClinVar (https://www.ncbi.nlm.nih.gov/ clinvar/) and Invitae (http://clinvitae.invitae.com/)

the majority were male (51.6\%), and had $\geq 100$ polyps in their colon (67.7\%) [52]. In addition, upper gastrointestinal polyps and desmoid tumors were observed in 41.9 and $9.7 \%$ of the study subjects, respectively. Ricker et al. described 9 Hispanic women from different regions with FAP with a mean age of diagnosis of 37.2 years. Among these women the most common extracolonic manifestation as upper gastric polyps [51]. The study describing Brazilian FAP patients reported that subjects had a mean age of 32.6 years (7-67 years), 79\% had upper gastrointestinal polyps, and 54\% had desmoid tumors [49]. The prevalence of extracolonic manifestations in the FAP patients of the Brazilian cohort was higher than in other Hispanic subpopulations. In summary, the clinical manifestations of FAP in Hispanics are similar to the one presented by non-Hispanic US Whites.

Clinical guidelines To guide genetic testing for FAP in individuals at high-risk, both the NCCN and the American Gastroenterology Association (AGA) have developed guidelines for physicians. The NCCN guidelines recommend genetic counseling for individuals with a personal history of $\geq 20$ colorectal adenomas, known $A P C$ deleterious mutation in the family, and personal manifestation of a desmoid tumor, cribriformular variant of papillary thyroid cancer, or hepatoblastoma [55]. Guidelines from the AGA for genetic counseling and testing include, personal history of $>10$ cumulative colorectal adenomas, family history of FAP, and family history of FAP-type extracolonic manifestations [56].

\section{Lynch Syndrome (LS)}

LS accounts for $2-4 \%$ of all CRC cases [44]. This syndrome is characterized by CRC at an early age and a high risk for a number of additional primary cancers, including endometrial and gastric cancer [57]. Approximately 1 in 35 individuals diagnosed with CRC has LS [58]. During their lifetime, individuals with LS will have up to a 70\% risk of developing CRC [58]; women will have up to a $45 \%$ risk of developing endometrial cancer [59].
Mutation spectrum Germline mutations in the DNA mismatch repair (MMR) genes, MLH1, MSH2, MSH6, PMS2 and EPCAM, causing the absence of MMR protein expression result in LS [60]. The most common genes mutated in LS are MLH1 and MSH2; close to 50\% of LS individuals have a mutation in $M L H 1$ [61]. In a review published by Dominguez-Valentín et al., the LS mutation spectrum in South American countries was described [62]. Pathogenic mutations in the MMR genes were identified in patients from Brazil [53], Argentina [63], Uruguay [64], and Colombia [65] (Table 3). Furthermore, the InSIGHT database contains additional information on MMR mutations in additional Hispanic subpopulations, Portugal, and Spain [53]. As seen in non Hispanic Whites, mutations in the $M L H 1$ gene are more common in Hispanic, Portuguese and Spanish populations, with the exception of Uruguay [64] and Caribbean Hispanics (Puerto Rico) [66] (Table 3). Data from Caribbean Hispanic patients showed that the mutation spectrum consisted mostly of $M S H 2$ mutations (66.7\%), followed by $M L H 1$ mutations (25.0\%) [66]. Mutations in the MSH6 gene have only been identified in the Caribbean Hispanics [66], Brazilians [53], Chileans [67], and Cubans [53]. There are no published mutations in the EPCAM gene among Hispanics cohorts. The mutation spectrum of MMR genes in Hispanic subgroups could be more varied, thus, additional studies in Hispanic subpopulations are needed.

Clinical presentation For $M L H 1$ mutation carriers, the CRC lifetime risk has been shown to be as high as $68 \%$ [68]. The prevalence of $M S H 2$ mutations in families with LS has been reported to range from 38 to $54 \%$, with a CRC lifetime risk of up to $68 \%$ [69]. The clinical presentation of LS in the Hispanic subgroups, is similar to what has been observed in NHW with a mean age of diagnosis of 30-44 years of age, endometrial cancer being the $2^{\text {nd }}$ most common LSassociated cancer, and colorectal tumor predominantly in the right colon [62]. 


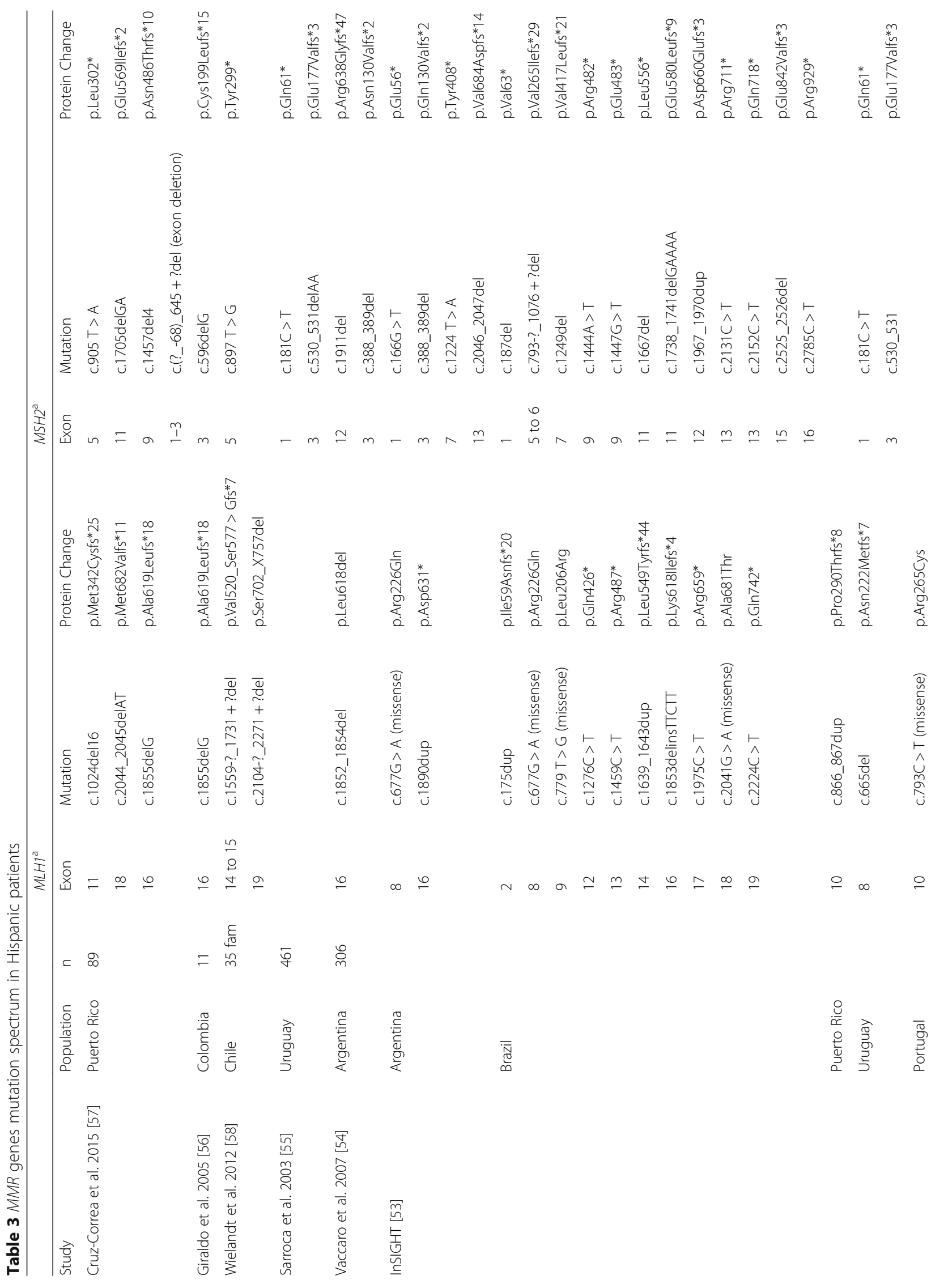


Cruz-Correa et al. Hereditary Cancer in Clinical Practice (2017) 15:3

Page 12 of 15

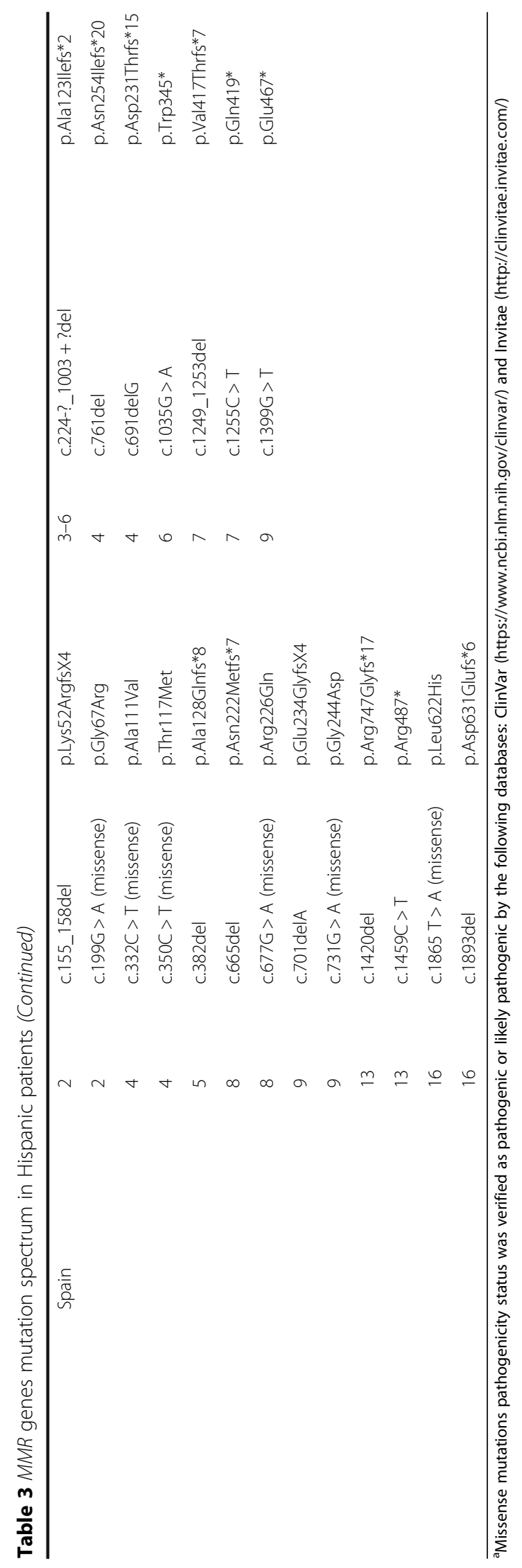


Clinical guidelines The identification of at-risk individuals for LS includes the clinical profile of the patient and molecular testing. The NCCN has published clinical guidelines to determine a patient's risk of having LS [55]. The Amsterdam and Bethesda criteria were established to help identify individuals that may harbor germline mutations in the MMR genes based on personal and family history of CRC [70]. The American Gastroenterology Association (AGA) also provides guidelines for the identifying at risk individuals and additionally guidelines for the screening of CRC among these LS individuals [71]. The AGA guidelines for LS testing are: to test MMR deficiency in newly diagnosed CRC cases, and to test individuals with CRC diagnosed at age $\leq 70$ or individuals older than 70 years of age who have a family history of LS [71]. Moreover, the AGA guidelines for screening for LS in these high-risk individuals or those affected by LS suggest colonoscopies every 1 to 2 years starting at age $20-25$ or starting 2 years younger than the youngest age at CRC diagnosis in the family [71]. Additional studies are needed to determine the utilization of established guidelines for Lynch Syndrome in Hispanics.

In addition, assessment of molecular markers in tumors, such as microsatellite instability (MSI) or loss of MMR protein expression, are used as molecular screening tools for identifying LS patients. Loss of MMR protein expression correlates with the presence of MSI and is indicative of a possible germline MMR gene mutation [72]. Genetic testing for LS is considered the "gold standard" for diagnosis. However, lack of detection of MMR protein expression by immunohistochemistry (IHC) can be a surrogate marker to diagnose LS when genetic testing is not available, due to limited accessibility to this type of test (lack of insurance coverage, economic hardships, limited infrastructure). Current NCCN and AGA guidelines recommend that genetic testing be offered to at-risk patients if the test influences the medical management of their condition or that of their atrisk relatives. However, an important concern is that these criteria may miss LS patients who do not meet criteria. LS screening of all CRC tumors has been shown to be cost-effective and is currently recommended by multiple professional societies $[55,71]$. As many as $1 / 3$ of women with LS may initially present with endometrial cancer without a history of CRC, thus universal screening for LS in endometrial cancer has also been proposed [73]. Currently, there are no reports in the literature on universal testing of Lynch Syndrome in Hispanic subgroups using IHC detection of MMR proteins, in contrast with non-Hispanic whites for which data is abundant.

\section{Multi-gene panel testing}

The Supreme Court of the US invalidated the patents made by Myriad Genetics@ that gave them the right to exclusively offer $B R C A$ genetic testing. This ruling permitted additional methods to sequence the $B R C A$ gene, as well as other genes, thus significantly reducing costs for genetic testing. Furthermore, major breakthroughs in next-generation sequencing (NGS) and a more comprehensive understanding of the genetic basis underlying hereditary cancers are shifting genetic testing for hereditary cancer from single gene testing to multiple gene panels. Several of the commercial companies offering cancer genetic screening are offering panels comprised of dozens of genes, including BRCA1/2 and the MMR genes, among others. Multi-gene testing would be especially beneficial to families who present a spectrum of different cancer types. Furthermore, the current reduced cost of NGS technology will allow laboratories across Latin America to perform studies on patients with the cancer syndromes discussed above to continue understanding the mutation spectrum and prevalence of mutations of Hispanic populations.

Although the future of hereditary cancer testing will undoubtedly reside in multi-gene panel testing, it presents some important challenges. Multi-gene panels include moderate penetrance genes with limited clinical utility. Furthermore, for many of the known hereditary cancer genes, is not clear whether the identification of a deleterious mutation warrants clinical measures beyond increased surveillance, particularly among understudied ethnic groups such as Hispanics [74]. In addition, multigene panel testing is likely to result in the identification of a higher number of variants of uncertain significance (VUS) and mutations with an undetermined clinical value. Currently, a lack of standardization across genetic laboratories regarding the analysis of the data as well as the clinical interpretation of results may lead to erroneous medical advice [75]. As research, education, and health policy development advances, these issues are likely to be resolved.

\section{Conclusion}

Over the last 10 years, the scientific community has conducted research to determine the prevalence and mutation spectrum of the genes associated with hereditary cancer syndromes in Hispanic populations. Genetic testing is an integral part of the treatment for cancer patients. As the standard of care in hereditary cancer testing shifts from single gene testing to multi-gene panel testing, it will be essential that ongoing research efforts focus on determining mutation penetrance and associated genetic risks. This information will ensure that the standard-of-care genetic testing is provided to all patients in need and that patients will have access to the latest advances in prevention and treatment of hereditary cancers. Examination of barriers to genetic testing and implementation of culturally sensitive 
educational programs will be essential to increase adherence. Moreover, integration of clinical genetic guidelines to health policy will enable implementation and sustainability of genetic medicine across Hispanic populations.

\section{Acknowledgments}

Furthermore, we want to thank the support of the Puerto Rico Clinical and Translational Research Consortium (8U54MD007587-03).

\section{Funding}

This work was supported by grant number U54CA096297 and grant number 1U54CA163071-01A1.

\section{Availability of data and materials}

The data analyzed during this study is available from each study analyzed in this review, the BIC database and the INSight database.

\section{Authors' contributions}

MCC and JPM conceived study, participated in design and wrote the manuscript. JD participated in design, provided articles to review and edited the manuscript. ME, RM, KR, SU, MG, MIO drafted and edited the manuscript. SP participated in study design, drafted and edited the manuscript.

All authors read and approved the final manuscript.

\section{Competing interests}

The authors declare that they have no competing interests.

\section{Consent for publication}

Not Applicable.

\section{Ethics approval and consent to participate}

Not Applicable.

\section{Author details}

${ }^{1}$ Department of Cancer Biology, University of Puerto Rico Comprehensive Cancer Center, San Juan, PR, USA. ${ }^{2}$ University of Puerto Rico Medical Sciences Campus, School of Medicine, San Juan, PR, USA. ${ }^{3}$ Ponce Health Sciences University, Ponce Research Institute, Ponce, PR, USA. ${ }^{4}$ Cancer Center, Auxilio Mutuo Hospital, San Juan, PR, USA. ${ }^{5}$ Puerto Rico Gastroenterology Association, San Juan, PR, USA. ${ }^{6}$ Department of Pediatrics, University of Puerto Rico School of Medicine, San Juan, PR, USA. 'Department of Pathology, University of Puerto Rico School of Medicine, San Juan, PR, USA. ${ }^{8}$ University of Puerto Rico Comprehensive Cancer Center, PMB711 Ave. De Diego 89 Ste. 105, San Juan, PR 00927-6346, USA.

Received: 2 April 2016 Accepted: 5 January 2017

Published online: 21 January 2017

\section{References}

1. U.S. Census Bureau (2009). Hispanics in the United States, Puerto Rico, and the U.S. Virgin Islands: 2000 Retrieved from: http://www.census.gov/content/ dam/Census/library/working-papers/2009/demo/POPtwps0084.pdf.

2. Avena $\mathrm{S}$, et al. Heterogeneity in genetic admixture across different regions of Argentina. PLoS One. 2012;7(4):e34695.

3. Siegel RL, et al. Cancer statistics for Hispanics/Latinos, 2015. CA Cancer Clin. 2015;65(6):457-80

4. Howlader N, et al. SEER cancer statistics review. J Natl Cancer Inst. 2013.

5. Howlader N, Noone AM, Krapcho M, Miller D, Bishop K, Altekruse SF, Kosary CL, Yu M, Ruhl J, Tatalovich Z, Mariotto A, Lewis DR, Chen HS, Feuer EJ, Cronin KA (eds). SEER Cancer Statistics Review, 1975-2013, National Cancer Institute. Bethesda, MD, http://seer.cancer.gov/csr/1975_2013/, based on November 2015 SEER data submission, posted to the SEER web site, April 2016

6. Beggs AD, Hodgson SV. Genomics and breast cancer: the different levels of inherited susceptibility. Eur J Hum Genet. 2009;17(7):855-6.

7. Pal T, et al. BRCA1 and BRCA2 mutations account for a large proportion of ovarian carcinoma cases. Cancer. 2005;104(12):2807-16.

8. Chen S, Parmigiani G. Meta-analysis of BRCA1 and BRCA2 penetrance. J Clin Oncol. 2007;25(11):1329-33.
9. Weitzel JN, et al. Prevalence and type of BRCA mutations in Hispanics undergoing genetic cancer risk assessment in the southwestern United States: a report from the Clinical Cancer Genetics Community Research Network. J Clin Oncol. 2013;31(2):210-6.

10. Weitzel JN, et al. Evidence for common ancestral origin of a recurring BRCA1 genomic rearrangement identified in high-risk Hispanic families. Cancer Epidemiol Biomarkers Prev. 2007;16(8):1615-20.

11. John EM, et al. Prevalence of pathogenic BRCA1 mutation carriers in 5 US racial/ethnic groups. JAMA. 2007;298(24):2869-76.

12. Ashton-Prolla P, Vargas FR. Prevalence and impact of founder mutations in hereditary breast cancer in Latin America. Genet Mol Biol. 2014;37(1 Suppl): 234-40.

13. Gomes MC, et al. Prevalence of BRCA1 and BRCA2 mutations in breast cancer patients from Brazil. Breast Cancer Res Treat. 2007;103(3):349-53.

14. Lourenco JJ, et al. BRCA1 mutations in Brazilian patients. Genet Mol Biol. 2004;27:500-4

15. Gutierrez-Espeleta G, et al. BRCA1 and BRCA2 mutations among familial breast cancer patients from Costa Rica. Clin Genet. 2012;82:484-8

16. Gonzalez-Hormazabal P, et al. Spectrum of BRCA1/2 point mutations and genomic rearrangements in high-risk breast/ovarian cancer Chilean families. Breast Cancer Res Treat. 2011;126(3):705-16.

17. Gallardo $M$, et al. Incidence of BRCA1 and BRCA2 mutations in 54 Chilean families with breast/ovarian cancer, genotype-phenotype correlations. Breast Cancer Res Treat. 2006;95(1):81-7.

18. Solano AR, et al. BRCA1 And BRCA2 analysis of Argentinean breast/ovarian cancer patients selected for age and family history highlights a role for novel mutations of putative south-American origin. Springerplus. 2012;1:20.

19. Abugattas J, et al. Prevalence of BRCA1 and BRCA2 mutations in unselected breast cancer patients from Peru. Clin Genet. 2015;88(4):371-5.

20. Rodriguez $\mathrm{AO}$, et al. BRCA1 and BRCA2 mutations among ovarian cancer patients from Colombia. Gynecol Oncol. 2012;124(2):236-43.

21. Torres $\mathrm{D}$, et al. High proportion of BRCA1/2 founder mutations in Hispanic breast/ovarian cancer families from Colombia. Breast Cancer Res Treat. 2007; 103(2):225-32

22. Lara $\mathrm{K}$, et al. BRCA1 and BRCA2 mutations in breast cancer patients from Venezuela. Biol Res. 2012:45(2):117-30.

23. Donenberg $\mathrm{T}$, et al. A high prevalence of BRCA1 mutations among breast cancer patients from the Bahamas. Breast Cancer Res Treat. 2011;125(2):591-6.

24. Rodriguez $R C$, et al. Prevalence of $B R C A 1$ and $B R C A 2$ mutations in breast cancer patients from Cuba. Fam Cancer. 2008:7(3):275-9.

25. Dutil J, et al. Identification of the prevalent BRCA1 and BRCA2 mutations in the female population of Puerto Rico. Cancer Genet. 2012;205(5):242-8.

26. Dutil J, et al. The spectrum of BRCA1 and BRCA2 alleles in Latin America and the Caribbean: a clinical perspective. Breast Cancer Res Treat. 2015; 154(3):441-53.

27. Calderon-Garcidueñas AL, et al. Clinical follow-up of Mexican women with early onset of breast cancer and mutations in the BRCA1 and BRCA2 genes. Salud Publica de Mexico. 2005:47:110-5.

28. Blay $\mathrm{P}$, et al. Mutational analysis of BRCA1 and BRCA2 in hereditary breast and ovarian cancer families from Asturias (Northern Spain). BMC Cancer. 2013:13:243

29. Fachal $L$, et al. Large genomic rearrangements of BRCA1 and BRCA2 among patients referred for genetic analysis in Galicia (NW Spain): delimitation and mechanism of three novel BRCA1 rearrangements. PLoS One. 2014;9(3): e93306.

30. de Juan Jimenez I, et al. Novel and recurrent BRCA1/BRCA2 mutations in early onset and familial breast and ovarian cancer detected in the Program of Genetic Counseling in Cancer of Valencian Community (eastern Spain). Relationship of family phenotypes with mutation prevalence. Fam Cancer. 2013;12(4):767-77.

31. Peixoto A, et al. The c.156_157insAlu BRCA2 rearrangement accounts for more than one-fourth of deleterious BRCA mutations in northern/centra Portugal. Breast Cancer Res Treat. 2009;114(1):31-8.

32. Ewald IP, et al. BRCA1 and BRCA2 rearrangements in Brazilian individuals with Hereditary Breast and Ovarian Cancer Syndrome. Genet Mol Biol. 2016; 39(2):223-31.

33. Weitzel JN, et al. Prevalence of BRCA mutations and founder effect in high-risk Hispanic families. Cancer Epidemiol Biomarkers Prev. 2005;14(7): 1666-71

34. de la Hoya M, et al. Genomic rearrangements at the BRCA1 locus in Spanish families with breast/ovarian cancer. Clin Chem. 2006;52(8):1480-5. 
35. Torres $D$, et al. Absence of the BRCA1 del (exons 9-12) mutation in breast/ ovarian cancer families outside of Mexican Hispanics. Breast Cancer Res Treat. 2009;117(3):679-81.

36. Peixoto $A$, et al. International distribution and age estimation of the Portuguese BRCA2 C.156_157insAlu founder mutation. Breast Cancer Res Treat. 2011;127(3):671-9.

37. Ewald IP, et al. Prevalence of the BRCA1 founder mutation c.5266dupin Brazilian individuals at-risk for the hereditary breast and ovarian cancer syndrome. Hered Cancer Clin Pract. 2011;9:12.

38. Dufloth RM, et al. Analysis of BRCA1 and BRCA2 mutations in Brazilian breast cancer patients with positive family history. Sao Paulo Med J. 2005; 123(4):192-7.

39. Gutierrez-Enriquez $S$, et al. Screening for large rearrangements of the BRCA2 gene in Spanish families with breast/ovarian cancer. Breast Cancer Res Treat. 2007:103(1):103-7.

40. Villarreal-Garza $C$, et al. Significant clinical impact of recurrent BRCA1 and BRCA2 mutations in Mexico. Cancer. 2015:121(3):372-8.

41. da Costa EC, et al. Founder effect of the BRCA1 5382insC mutation in Brazilian patients with hereditary breast ovary cancer syndrome. Cancer Genet Cytogenet. 2008;184(1):62-6.

42. Daly MB, et al. Genetic/familial high-risk assessment: breast and ovarian version 1.2014. J Natl Compr Canc Netw. 2014;12(9):1326-38.

43. Levy $D E$, et al. Underutilization of BRCA1/2 testing to guide breast cancer treatment: black and Hispanic women particularly at risk. Genet Med. 2011; 13(4):349-55.

44. Jasperson KW, et al. Hereditary and familial colon cancer. Gastroenterology. 2010;138(6):2044-58

45. Munck $A$, et al. Evaluation of guidelines for management of familial adenomatous polyposis in a multicenter pediatric cohort. J Pediatr Gastroenterol Nutr. 2011;53(3):296-302.

46. Half E, Bercovich D, Rozen P. Familial adenomatous polyposis. Orphanet J Rare Dis. 2009:4:22

47. Kinzler KW, et al. Identification of FAP locus genes from chromosome 5q21. Science. 1991;253(5020):661-5.

48. Bisgaard ML, et al. Familial adenomatous polyposis (FAP): frequency, penetrance, and mutation rate. Hum Mutat. 1994;3(2):121-5.

49. Torrezan GT, et al. Mutational spectrum of the APC and MUTYH genes and genotype-phenotype correlations in Brazilian FAP, AFAP, and MAP patients. Orphanet J Rare Dis. 2013;8:54.

50. Zeichner SB, et al. A De Novo Germline APC Mutation (3927del5) in a Patient with Familial Adenomatous Polyposis: Case Report and Literature Review. Clin Med Insights Oncol. 2012;6:315-23.

51. Ricker C, et al. Familial Adenomatous Polyposis (FAP) in 9 Hispanic women. Hered Cancer Clin Pract. 2010;2010(8):P18.

52. Cruz-Correa $\mathrm{M}$, et al. Clinical characterization and mutation spectrum in Hispanic families with adenomatous polyposis syndromes. Fam Cancer. 2013;12(3):555-62.

53. Plazzer JP, et al. The InSiGHT database: utilizing 100 years of insights into Lynch Syndrome. Fam Cancer. 2013;12:173-80.

54. Fearnhead NS, Britton MP, Bodmer WF. The ABC of APC. Hum Mol Genet. 2001;10(7):721-33

55. National Comprehensive Cancer Network. Genetic/familial high risk assessment: colorectal cancer. 2016. Version 1.2016.

56. Syngal S, et al. ACG clinical guideline: Genetic testing and management of hereditary gastrointestinal cancer syndromes. Am J Gastroenterol. 2015; 110(2):223-62. quiz 263.

57. Aarnio M, et al. Life-time risk of different cancers in hereditary non-polyposis colorectal cancer (HNPCC) syndrome. Int J Cancer. 1995;64(6):430-3.

58. Hampel $\mathrm{H}$, et al. Feasibility of screening for Lynch syndrome among patients with colorectal cancer. J Clin Oncol. 2008;26(35):5783-8.

59. Stoffel $\mathrm{E}$, et al. Calculation of risk of colorectal and endometrial cancer among patients with Lynch syndrome. Gastroenterology. 2009;137(5):1621-7.

60. Pritchard CC, Grady WM. Colorectal cancer molecular biology moves into clinical practice. Gut. 2011;60(1):116-29.

61. Peltomaki P. Role of DNA mismatch repair defects in the pathogenesis of human cancer. J Clin Oncol. 2003:21(6):1174-9.

62. Dominguez-Valentin $M$, et al. Mutation spectrum in South American Lynch syndrome families. Hered Cancer Clin Pract. 2013;11(1):18.

63. Vaccaro CA, et al. Hereditary nonpolyposis colorectal cancer (Lynch Syndrome) in Argentina: report from a referral hospital register. Dis Colon Rectum. 2007:50(10):1604-11.
64. Sarroca C, et al. Frequency of hereditary non-polyposis colorectal cancer among Uruguayan patients with colorectal cancer. Clin Genet. 2005:68(1):80-7.

65. Giraldo A, et al. MLH1 and MSH2 mutations in Colombian families with hereditary nonpolyposis colorectal cancer (Lynch syndrome)-description of four novel mutations. Fam Cancer. 2005;4(4):285-90.

66. Cruz-Correa $\mathrm{M}$, et al. Clinical characterization and mutation spectrum in Caribbean Hispanic families with Lynch syndrome. Fam Cancer. 2015;14(3): 415-25.

67. Weilandt AM, et al. Lynch Syndrome: selection of families by microsatellite instability and immunohistochemistry. Rev Medica Chile. 2012;140:1132-9.

68. Choi $\mathrm{YH}$, et al. Penetrance of colorectal cancer among MLH1/MSH2 carriers participating in the colorectal cancer familial registry in Ontario. Hered Cancer Clin Pract. 2009;7(1):14.

69. Barnetson RA, et al. Identification and survival of carriers of mutations in DNA mismatch-repair genes in colon cancer. N Engl J Med. 2006;354(26): 2751-63.

70. Umar A, et al. Revised Bethesda Guidelines for hereditary nonpolyposis colorectal cancer (Lynch syndrome) and microsatellite instability. J Natl Cancer Inst. 2004;96(4):261-8.

71. Giardiello FM, et al. Guidelines on genetic evaluation and management of Lynch syndrome: a consensus statement by the US Multi-society Task Force on colorectal cancer. Am J Gastroenterol. 2014;109(8):1159-79.

72. Shia J. Immunohistochemistry versus microsatellite instability testing for screening colorectal cancer patients at risk for hereditary nonpolyposis colorectal cancer syndrome. Part I. The utility of immunohistochemistry. J Mol Diagn. 2008;10(4):293-300.

73. Wang $Y$, et al. Lynch syndrome related endometrial cancer: clinical significance beyond the endometrium. J Hematol Oncol. 2013;6:22

74. Robson M. Multigene panel testing: planning the next generation of research studies in clinical cancer genetics. J Clin Oncol. 2014;32(19):1987-9.

75. Ortiz AP, et al. Awareness of direct-to-consumer genetic tests and use of genetic tests among Puerto Rican adults, 2009. Prev Chronic Dis. 2011;8(5):A110.

76. Delgado $L$, et al. BRCA1 and BRCA2 germline mutations in Uruguayan breast and breast-ovarian cancer families. Identification of novel mutations and unclassified variants. Breast Cancer Res Treat. 2011;128(1):211-8.

77. Torres-Mejia G, et al. Recurrent BRCA1 and BRCA2 mutations in Mexican women with breast cancer. Cancer Epidemiol Biomarkers Prev. 2015;24(3): 498-505.

\section{Submit your next manuscript to BioMed Central and we will help you at every step:}

- We accept pre-submission inquiries

- Our selector tool helps you to find the most relevant journal

- We provide round the clock customer support

- Convenient online submission

- Thorough peer review

- Inclusion in PubMed and all major indexing services

- Maximum visibility for your research

Submit your manuscript at www.biomedcentral.com/submit

) BioMed Central 